\title{
Diagnóstico de alergia a alimentos
}

\author{
Dr. José Antonio Ortega Martell, ${ }^{*}$ \\ Dra. Rosa Elena Huerta Hernández ${ }^{\ddagger}$
}

\begin{abstract}
RESUMEN
La alergia a un alimento es una reacción adversa que ocurre por un mecanismo inmunológico específico hacia un antígeno de ese alimento. Existen varias hipótesis que intentan explicar las causas del incremento reciente en la aparición de alergias alimentarias en la población; sin embargo, ninguna ha demostrado ser la única que pueda explicar irrefutablemente este aumento. El mecanismo fisiopatológico común entre las formas de alergia a alimentos mediadas por IgE y no mediadas por lgE, se encuentra en la falla de la tolerancia clínica e inmunológica hacia ese alimento. Actualmente, los métodos diagnósticos aprobados son la historia clínica, la determinación de IgE específica y la prueba de reto oral. Existen otros métodos en investigación que pueden ayudar a un diagnóstico más oportuno y efectivo de la enfermedad.
\end{abstract}

Palabras clave: Alergia a alimentos, diagnóstico, tolerancia.

\begin{abstract}
Food allergy is an adverse reaction that occurs through a specific immune mechanism to a food antigen. There are several hypotheses that attempt to explain the causes of the recent increase in the emergence of food allergies in the population; however, none has been shown to be the only one that can irrefutably explain this increase. The common pathophysiological mechanism between IgE-mediated and non-IgEmediated forms of food allergy relays in the failure of clinical and immunological tolerance to that food. Currently the approved diagnostic methods are the medical history, the specific IgE determination and the oral challenge test. There are other research methods that can help a more timely and effective diagnosis of the disease.
\end{abstract}

Keyword: Food allergy, diagnostic, tolerance.

\section{CONCEPTOS CLAVE}

- El diagnóstico de la alergia a un alimento inicia con una definición adecuada y el conocimiento de los mecanismos fisiopatológicos que la ocasionan.

- La alergia a alimentos puede ser causada por mecanismos mediados por IgE, o por mecanismos no mediados por IgE, o por ambos.
- El estudio de los mecanismos naturales de tolerancia hacia los alimentos es clave para entender la fisiopatología.

- Actualmente los métodos diagnósticos aprobados son la historia clínica, la determinación de IgE específica y la prueba de reto oral.

- Existen otros métodos en investigación que pueden ayudar a un diagnóstico más oportuno y efectivo de la enfermedad.

\footnotetext{
* Profesor de Inmunología. Instituto de Ciencias de la Salud. Universidad Autónoma del Estado de Hidalgo.

‡ Alergólogo Pediatra. Directora de Clínica de Alergia Pediátrica, Pachuca, Hidalgo.
} 
Vol. 29, Núm. 1 • Enero-Abril 2020

\section{INTRODUCCIÓN}

La alergia a alimentos es un problema de salud mundial que se ha incrementado importantemente en los últimos 30 años y que parece ir de la mano con los cambios en el estilo de vida y la forma de alimentación de los seres humanos en diferentes comunidades, tanto urbanas como rurales. Para poder hacer un diagnóstico adecuado de alergia a alimentos es necesario establecer la definición y conocer la fisiopatología de la enfermedad, ya que sólo así se podrá tener un lenguaje común y una guía que dirija las acciones no sólo para el diagnóstico sino también para el tratamiento y para la prevención. El objetivo de este capítulo es resumir el conocimiento actual que se tiene sobre la alergia alimentaria y en especial sobre la forma correcta de hacer el diagnóstico.

\section{DEFINICIÓN}

La alergia a un alimento es una reacción adversa que ocurre por un mecanismo inmunológico específico hacia un antígeno de ese alimento. ${ }^{1}$ El mecanismo inmunológico más frecuente es mediado por anticuerpos IgE específicos que activan una respuesta rápida en la primera hora después de la exposición a ese alimento. Sin embargo, también hay formas de alergia a alimentos que no ocurren por mecanismos mediados por IgE sino por células inmunológicas (linfocitos) con receptores específicos hacia un antígeno de ese alimento y que ocurren en forma más tardía. En algunas formas de alergia a alimentos también se pueden encontrar evidencias de ambos mecanismos por lo que se han considerado como formas mixtas. En la tabla 1 se resumen estos tipos de alergia a alimentos y se enlistan algunos ejemplos de cada uno de ellos.

\section{EPIDEMIOLOGÍA}

Existe gran variación en la incidencia y prevalencia de alergia a alimentos en los estudios epidemiológicos que se han llevado a cabo en diferentes países y esta diferencia se debe en gran medida a la variabilidad en la definición de alergia alimentaria que se establece en cada estudio, así como en los métodos para confirmarla. Actualmente varios estudios con metodología similar han encontrado una frecuencia de pacientes con cuadro clínico compatible con alergia alimentaria de hasta $10 \%$ en la población general, aunque al confirmarse con pruebas de IgE específica (sérica o pruebas cutáneas) y con reto oral controlado, la frecuencia puede disminuir hasta llegar a sólo 1-2\%. En las últimas tres décadas el incremento en la aparición de alergia alimentaria se ha presentado predominantemente en países más industrializados, más en niños que en adultos y los alimentos que más frecuentemente se reportan como causantes
Tabla 1: Definición y formas clínico-patológicas descritas en alergia a alimentos.

\begin{tabular}{|c|c|c|}
\hline \multicolumn{3}{|c|}{$\begin{array}{l}\text { Alergia a alimentos, } \\
\text { Reacción mediada por un mecanismo inmunológico } \\
\text { específico hacia un antígeno alimentario }\end{array}$} \\
\hline Mediada por IgE & Mixta & No mediada por $\lg \mathrm{E}$ \\
\hline Inicio < 1 hora, agudo & Inicio > 1 hora, crónico & Inicio > 1 hora, crónico \\
\hline $\begin{array}{l}\text { - Anafilaxia } \\
\text { - Urticaria y } \\
\text { angioedema } \\
\text { - Síndrome de alergia } \\
\text { oral } \\
\text { - Síndrome gastroin- } \\
\text { testinal inmediato } \\
\text { - Rinitis, asma } \\
\text { - Anafilaxia por } \alpha \text {-Gal } \\
\text { - Anafilaxia inducida } \\
\text { por ejercicio-alimentos }\end{array}$ & $\begin{array}{l}\text { - Dermatitis atópica } \\
\text { - Gastroenteropatías } \\
\text { eosinofílicas: } \\
\text { - Esofagitis } \\
\text { - Gastritis } \\
\text { - Enteritis } \\
\text { - Colitis }\end{array}$ & $\begin{array}{l}\text { - Enterocolitis inducida } \\
\text { por proteínas (FPIES) } \\
\text { - Proctocolitis inducida } \\
\text { por proteínas (FPIAP) } \\
\text { - Síndrome de Heiner } \\
\text { - Dermatitis alérgica por } \\
\text { contacto }\end{array}$ \\
\hline
\end{tabular}

son: leche, huevo, cacahuates, nueces, trigo, soya, pescado, mariscos y soya. ${ }^{1,2}$

\section{FISIOPATOLOGÍA}

Existen varias hipótesis que intentan explicar las causas de este incremento reciente en la aparición de alergias alimentarias en la población; sin embargo, ninguna ha demostrado ser la única que pueda explicar irrefutablemente este incremento. Es muy probable que la explicación se encuentre en una combinación de varias, o tal vez de todas, estas hipótesis. En la tabla 2 se describen algunas de las hipótesis que actualmente presentan mayor evidencia científica sólida.

El mecanismo fisiopatológico común entre las formas de alergia a alimentos mediadas por IgE y no mediadas por IgE, se encuentra en la falla de la tolerancia clínica e inmunológica hacia ese alimento. ${ }^{3}$ Tanto la inducción como el mantenimiento de esta tolerancia inmunológica depende de la generación activa de células $T$ reguladoras específicas para antígenos alimentarios. Este proceso está influenciado por factores genéticos (por ejemplo los genes FOXP3) y también por factores epigenéticos condicionados por el medio ambiente (por ejemplo, dieta, microbiota y sus productos). La sensibilización hacia una antígeno alimentario puede ocurrir por la exposición al mismo tanto por la vía digestiva, como por la vía cutánea o inclusive la vía respiratoria, en especial cuando existe una falla en los mecanismos de protección al estar inflamadas y dañadas estas barreras. Las células dendríticas CD103+ en las mucosas y CD11b+en la piel normalmente son las encargadas 
Vol. 29, Núm. 1 Enero-Abril 2020

Tabla 2: Hipótesis y comentarios acerca de los factores de riesgo para el desarrollo de alergia a alimentos.

\begin{tabular}{|c|c|c|}
\hline Hipótesis & Descripción & Comentarios \\
\hline Exposición microbiana (higiene) & $\begin{array}{l}\text { Exposición reducida afecta } \\
\text { regulación inmunológica }\end{array}$ & $\begin{array}{l}\text { Evidencia limitada en cambios de microbiota, uso } \\
\text { de pre-/probióticos, cesárea, antibióticos, mascotas }\end{array}$ \\
\hline $\begin{array}{l}\text { Exposición alimentaria } \\
\text { (retraso en introducción) }\end{array}$ & $\begin{array}{c}\text { Exposición temprana reduce } \\
\text { o favorece alergia }\end{array}$ & $\begin{array}{c}\text { Evidencia limitada en dieta materna } \\
\text { durante el embarazo o lactancia, } \\
\text { fórmulas hipoalergénicas }(\mathrm{pH} \circ \mathrm{eH})\end{array}$ \\
\hline $\begin{array}{l}\text { Exposición dual } \\
\text { (vía cutánea versus vía oral) }\end{array}$ & $\begin{array}{l}\text { Exposición cutánea evita tolerancia } \\
\text { oral al alimento }\end{array}$ & $\begin{array}{l}\text { Fuerte evidencia con cacahuate en niños de alto } \\
\text { riesgo, evidencia limitada en otros alimentos }\end{array}$ \\
\hline Inmunomodulación nutricional & Factores reguladores en alimentos & $\begin{array}{l}\text { Evidencia limitada con vitamina } D \\
\text { omega } 3 \text {, folatos y antioxidantes }\end{array}$ \\
\hline $\begin{array}{l}\text { Otros factores (obesidad, aditivos, } \\
\text { modificación genética) }\end{array}$ & $\begin{array}{c}\text { Obesidad }=\text { inflamación, } \\
\text { aditivos }=\text { tóxicos }, \text { genética }=\text { nuevos alérgenos }\end{array}$ & $\begin{array}{l}\text { Datos muy limitados y sólo especulativos } \\
\text { sobre los efectos en la regulación inmunológica } \\
\text { y en los posibles cambios epigenéticos }\end{array}$ \\
\hline
\end{tabular}

de atrapar, procesar y presentar estos antígenos alimentarios a los linfocitos $\mathrm{T}$ en las zonas linfoides favoreciendo su diferenciación hacia células $T$ reguladoras específicas para estos antígenos. Se ha demostrado que la producción de citocinas de alarma como la IL33, IL-25 y la TSLP por el epitelio dañado activa la expresión de OX40 ligando en las células dendríticas y así puede favorecer la diferenciación de linfocitos $\mathrm{T}$ hacia linfocitos Th2 en vez de $\mathrm{T}$ reguladores, cambiando la respuesta de tolerancia hacia una respuesta inflamatoria mediada por Th2, eosinófilos, células cebadas y linfocitos B productores de IgE específica para ese antígeno alimentario (alérgeno). La IL-33 también puede activar las células innatas linfoides tipo 2 (ILC2) las cuales pueden producir citocinas similares al patrón Th2: IL-4, IL-5, IL-9 e IL-13. La IL-4 favorece la síntesis de IgE e inhibe la diferenciación de células $T$ reguladoras, la IL-5 atrae y activa a los eosinófilos, la IL-9 activa a las células cebadas y la IL-13 favorece la producción de moco y el remodelado tisular. En las formas de alergia a alimentos no mediada por IgE se ha demostrado la participación de linfocitos Th2 y tal vez de células ILC2, pero ambas con baja producción de IL-4 y mayor producción de IL-5, IL-9 e IL-13, probablemente en respuesta a diferentes citocinas y mediadores producidos por el epitelio, favoreciendo una reacción inflamatoria sin la participación de anticuerpos IgE (Figura 1).

\section{DIAGNÓSTICO}

Habiendo ya definido la alergia a alimentos y entendido los mecanismos que la originan, podemos utilizar mejor los métodos más útiles para el diagnóstico. En esta sección describiremos cuáles son actualmente los métodos diagnósticos aprobados, así como los métodos no aprobados y los métodos que se encuentran en investigación.

\section{MÉTODOS DIAGNÓSTICOS APROBADOS}

a. Historia clínica.

b. Determinación de IgE específica.

c. Prueba de reto oral.

La historia clínica detallada y bien dirigida sigue siendo la «prueba» que mejor orienta al clínico hacia el diagnóstico de alergia a alimentos. ${ }^{2}$ Interrogar los antecedentes familiares de atopia, buscar antecedentes personales de otras enfermedades alérgicas en el paciente, conocer los detalles de cómo ocurrió la reacción después de la ingesta del alimento y qué otros factores pueden estar asociados, el tipo de signos y síntomas que se presentan, la intensidad y duración de los síntomas, la respuesta al tratamiento y la recurrencia en la presentación del cuadro, puede ser suficiente para descartar una alergia a alimentos o para justificar las pruebas que confirmen el diagnóstico (Figura 2). Si la historia clínica no revela datos consistentes con alergia a alimentos, se deben investigar otros mecanismos que hayan ocasionado esa reacción, como la contaminación del alimento con toxinas o inclusive histamina o precursores de ella, o una intolerancia metabólica como la intolerancia a la lactosa, por ejemplo, o algunas otras reacciones no dependientes de mecanismos inmunológicos específicos. En cambio, si la historia clínica es consistente con una respuesta de alergia a alimentos, se debe ahora investigar con más detalle sobre la velocidad y el tipo de la reacción para conocer si hay o no datos relacionados con un mecanismo inmunológico mediado por anticuerpos IgE (Tabla 1). Si la historia clínica sugiere un mecanismo mediado por IgE entonces se deben hacer pruebas que confirmen la presencia de IgE específica hacia el alérgeno sospechoso. Esta investigación se puede hacer in vivo mediante las pruebas cutáneas por el método de Prick o se puede hacer in vitro buscando IgE sérica 
Vol. 29, Núm. 1 • Enero-Abril 2020

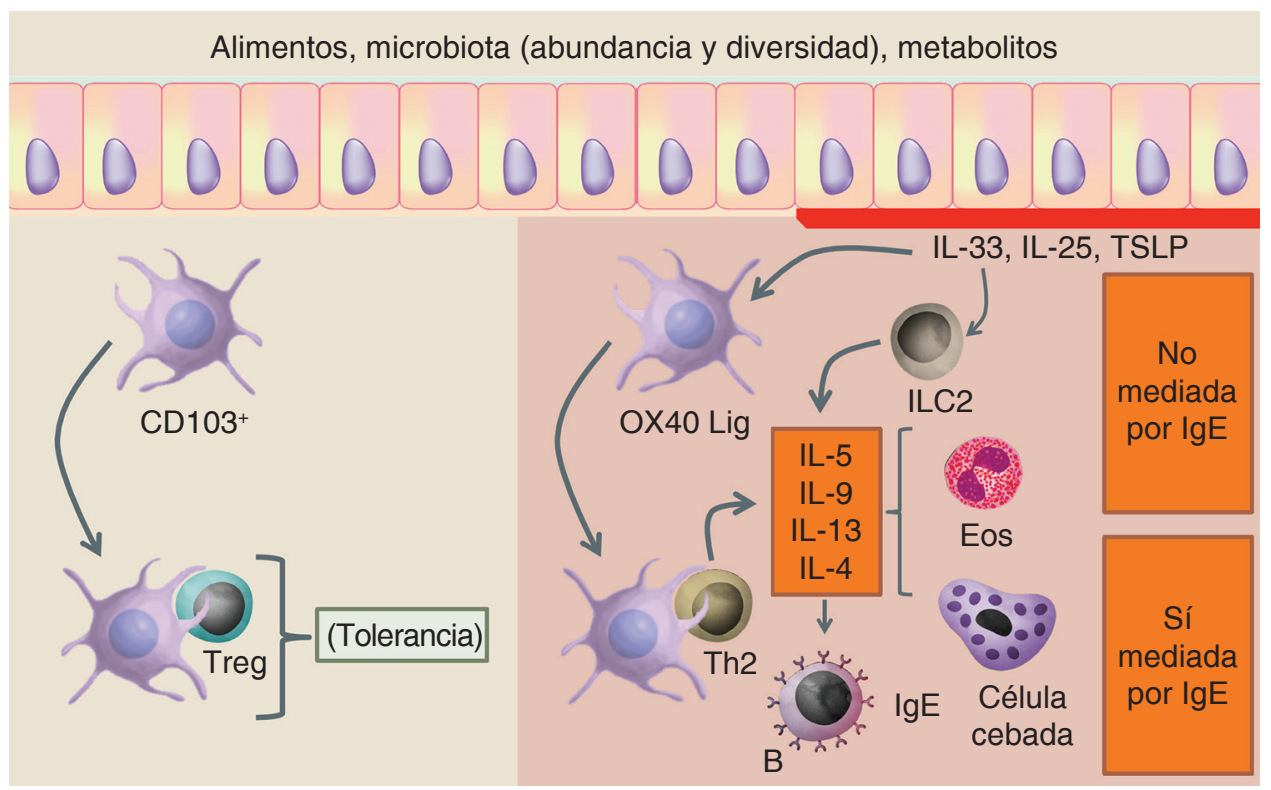

\section{Figura 1:}

Mecanismo fisiopatológico en alergia a alimentos. específica hacia el alérgeno sospechoso por métodos de quimioluminiscencia. En general ambas pruebas son útiles, demostrando en las investigaciones mayor sensibilidad que especificidad hacia los diferentes alérgenos alimentarios; sin embargo, la interpretación adecuada de los resultados en ambos casos depende de la experiencia del especialista que las solicita y evalúa. Los resultados positivos de ambas pruebas son útiles siempre y cuando haya una correlación clínica con los síntomas del paciente cuando se expone al alimento. Si hay una prueba que demuestre la presencia de IgE específica hacia el alimento pero sin correlación clínica al consumirlo, sólo se puede concluir que existe sensibilización pero no una respuesta alérgica. Esto ocurre frecuentemente cuando los niveles de IgE sérica específica se encuentran en rangos bajos o la positividad en la prueba cutánea no es muy intensa comparada con los controles positivo y negativo.

Si la búsqueda de IgE específica para el alérgeno es negativa entonces debe realizarse una prueba de reto oral controlado con el alimento sospechoso. Esta prueba de reto oral debe hacerse bajo supervisión estrecha del médico y con todos los medicamentos y recursos necesarios para tratar una reacción que pudiera presentarse durante el reto. La prueba de reto oral puede ser positiva tanto en mecanismos mediados por IgE, como en mecanismos no mediados por IgE, ya que se trata de una exposición directa del sistema inmunológico gastrointestinal al alimento, por lo que para diferenciarlos se requiere la evaluación previa descrita también en el algoritmo de la figura 2.

Cuando no hay datos sugestivos de un mecanismo mediado por lgE, es útil saber si la manifestación pri- maria del paciente es una forma clínica sugestiva de un mecanismo mixto (por ejemplo, dermatitis atópica o esofagitis eosinofílica) ya que en este caso se pueden hacer tanto las pruebas de búsqueda de IgE específica hacia el alérgeno como la prueba de reto oral. En las formas clínicas con mecanismos mixtos, la prueba de reto oral frecuentemente es la que determina el diagnóstico y especialmente en la esofagitis eosinofílica el número de eosinófilos que se encuentren en una biopsia esofágica también puede ser clave para el diagnóstico. Si no hay dermatitis atópica ni esofagitis eosinofílica o alguna otra forma mixta, entonces se trata de una manifestación clínica no mediada por IgE (como FPIES, por ejemplo) y la prueba de eliminación del alimento (con mejoría de los síntomas en los siguientes días) seguida de la prueba de reto oral controlado puede confirmar el diagnóstico. ${ }^{4}$

Después de confirmarse el diagnóstico de alergia al alimento sospechoso, es importante hacer reevaluaciones periódicas para saber la evolución del padecimiento, incluyendo la resolución de la alergia. El tiempo para reevaluar al paciente dependerá de su edad, el tipo de alimento alergénico y la forma clínico-patológica que presente.

\section{MÉTODOS DIAGNÓSTICOS NO APROBADOS}

Existe una serie de exámenes que no han demostrado ser útiles para el diagnóstico de alergia a alimentos y que por lo tanto no deben realizarse en forma rutinaria en los pacientes con sospecha de alergia a alimentos. En esta serie se encuentran las pruebas cutáneas in- 
Vol. 29, Núm. 1 • Enero-Abril 2020

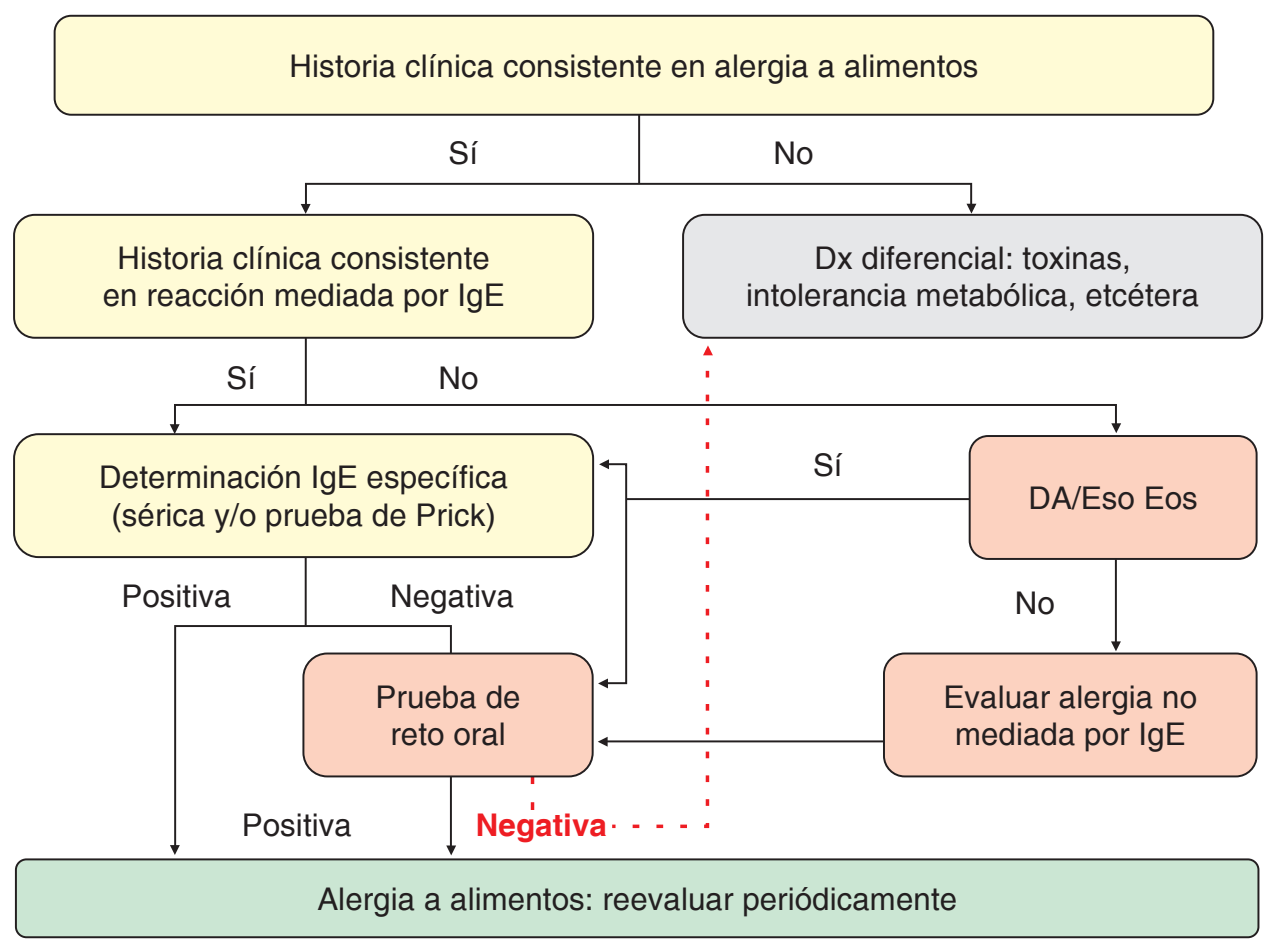

Figura 2:

Algoritmo diagnóstico en alergia a alimentos. tradérmicas, la medición de IgE sérica total, las pruebas de parche, la medición de proteínas catiónicas eosinofílicas y las pruebas de activación de basófilos. También hay otra serie de estudios no estandarizados que definitivamente no se recomiendan para el diagnóstico de alergia a alimentos, como la quinesiología aplicada, la medición de IgG4 o IgG contra antígenos alimentarios, las pruebas electrodérmicas y el análisis de minerales en el cabello. ${ }^{2}$

\section{MÉTODOS DIAGNÓSTICOS EN INVESTIGACIÓN}

Además de medir IgE específica dirigida contra el extracto alergénico completo, se pueden buscar anticuerpos IgE específicos contra diferentes componentes alergénicos (epítopos) de esa proteína. Esta medición de IgE específica contra componentes alergénicos es más específica y permite diferenciar entre epítopos de reactividad cruzada entre varios alérgenos con poca importancia clínica y los principales epítopos que sí correlacionen con la gravedad de los síntomas. Aunque actualmente ya se pueden hacer estas pruebas, aún se siguen investigando cuáles son los epítopos más importantes en cada alérgeno y qué variaciones puede haber entre diferentes grupos de pacientes para poder hacer un mejor diagnóstico por componentes alergénicos en un futuro cercano. Otros estudios que se encuentran en investigación son los relacionados con la forma en la que se reacciona hacia el alérgeno y las moléculas, células y genes que pueden estar involucrados. Estas pruebas incluyen estudios del genoma, el epigenoma, el transcriptoma, el proteoma, el metaboloma, el microbioma y el exposoma. ${ }^{5}$

\section{TRATAMIENTO}

Una vez que se ha confirmado el diagnóstico, actualmente el tratamiento para la mayoría de los casos de alergia a alimentos consiste en tratar los síntomas de la reacción que se presente y evitar la ingesta y exposición a ese alimento. Para evitar la exposición accidental nuevamente a ese alimento, el paciente y sus familiares deben recibir una orientación adecuada por expertos en nutrición sobre cuáles son los alimentos que pueden contener inclusive trazas de la proteína alergénica y cómo sustituir su ausencia con una dieta bien equilibrada. En los casos graves de alergia a alimentos como la anafilaxia, el paciente y su familia deben saber cómo reconocer tempranamente los síntomas y cómo usar la epinefrina intramuscular de manera oportuna para evitar que avance la reacción. Actualmente se están investigando diferentes protocolos de inmunoterapia oral para desensibilizar al paciente con este tratamiento y así evitar una reacción grave al exponerse accidentalmente al alimento. Los avances en 
Vol. 29, Núm. 1 • Enero-Abril 2020

estos protocolos han demostrado que se puede lograr en forma efectiva la desensibilización pero aún no se ha podido alcanzar una tolerancia duradera después de terminar el tratamiento. ${ }^{3}$

\section{PREVENCIÓN}

La alimentación del niño menor de dos años con leche humana y en forma exclusiva durante los primeros seis meses ha demostrado ser útil para retrasar la aparición de síntomas de alergia en niños de alto riesgo de padecerla; sin embargo, los estudios no han logrado encontrar aún un efecto preventivo contundente. Esto puede estar relacionado con la variabilidad en los estudios y la dificultad de estandarizar los protocolos de lactancia materna (exclusiva o no, tiempo, factores nutricionales individuales, etcétera). También se ha investigado si la introducción temprana o tardía de alimentos en la dieta complementaria en el primer año de vida tiene efectos sobre la prevención de alergia alimentaria y se ha encontrado que el retraso en la ingesta (después de los seis meses) puede favorecer la sensibilización para la mayoría de los alimentos y en cambio la introducción temprana (entre los cuatro y seis meses) puede ayudar a la tolerancia inmunológica hacia el alimento. Se discute aún si las fórmulas infantiles hidrolizadas en forma parcial $(\mathrm{pH})$ o extensa $(\mathrm{eH})$, asociadas o no a prebióticos y probióticos, pueden tener algún efecto importante en la prevención de la alergia alimentaria y otras enfermedades alérgicas, pero aún faltan más estudios bien controlados para demostrarlo..$^{2,6}$

\section{PREGUNTAS DE AUTOEVALUACIÓN}

1. ¿Cuál de las siguientes formas clínicas de alergia a alimentos es ocasionada por un mecanismo inmunológico dependiente de $\lg \mathrm{E}$ ?
a. Síndrome de enterocolitis inducida por proteínas (FPIES).
b. Síndrome de proctocolitis alérgica inducida por proteínas.
c. Síndrome de Heiner.
d. Síndrome de alergia oral.
e. Enfermedad celiaca.

2. ¿Cuál de las siguientes formas clínicas de alergia a alimentos es ocasionada por un mecanismo inmunológico no dependiente de IgE?
a. Anafilaxia.
b. Urticaria y angioedema.
c. Síndrome de alergia oral.
d. Síndrome de enterocolitis inducida por proteínas (FPIES).
e. Hipersensibilidad gastrointestinal inmediata.

3. ¿Cuál de las siguientes formas clínicas de alergia a alimentos es ocasionada por un mecanismo inmunológico mixto?
a. Anafilaxia.
b. Anafilaxia inducida por ejercicio y alimentos.
c. Proctocolitis alérgica inducida por proteínas.
d. Esofagitis eosinofílica.
e. Hipersensibilidad gastrointestinal inmediata.

4. ¿Cuál de los siguientes métodos no está aprobado para el diagnóstico de alergia a alimentos?
a. Historia clínica detallada.
b. Medición de IgE específica al alérgeno.
c. Medición de IgG4 específica al alérgeno.
d. Prueba cutánea por el método de Prick.
e. Prueba de reto oral controlado y supervisado.

\section{BIBLIOGRAFÍA}

1. Ebisawa M, Ito K, Fujisawa T. Japanese guidelines for food allergy. Allergol Int. 2017; 66 (2): 248-264.

2. Sicherer SH, Sampson HA. Food allergy: a review and update on epidemiology, pathogenesis, diagnosis, prevention, and management. J Allergy Clin Immunol. 2018; 141: 41-58.

3. Sampson HA, O'Mahony L, Burks AW, Plaut M, Lack G, Akdis CA. Mechanisms of food allergy. J Allergy Clin Immunol. 2018; 141: 11-19.

4. Nowak-Węgrzyn A, Chehade M, Groetch ME, Spergel JM, Wood RA, Allen K, et al. International consensus guidelines for the diagnosis and management of food protein-induced enterocolitis syndrome: executive summary-Workgroup Report of the Adverse Reactions to Foods Committee, American Academy of Allergy, Asthma \& Immunology. $J$ Allergy Clin Immunol. 2017; 139: 1111-1126.

5. Dhondalay GK, Rael E, Acharya S, Zhang W, Sampath V, Galli SJ et al. Food allergy and omics. J Allergy Clin Immunol. 2018; 141 (1): 20-29.

6. Du Toit G, Sampson HA, Plaut M, Burks AW, Akdis CA, Lack G. Food allergy: Update on prevention and tolerance. $J$ Allergy Clin Immunol. 2018; 141 (1): 30-40.

Dirección para correspondencia: Dr. José Antonio Ortega Martell E-mail: drortegamartell@prodigy.net.mx 